\title{
Pelo desejo da língua: Uma entrevista com o Professor Luis Ernesto Behares
}

\section{An Interview with the teacher Luis Ernesto Behares}

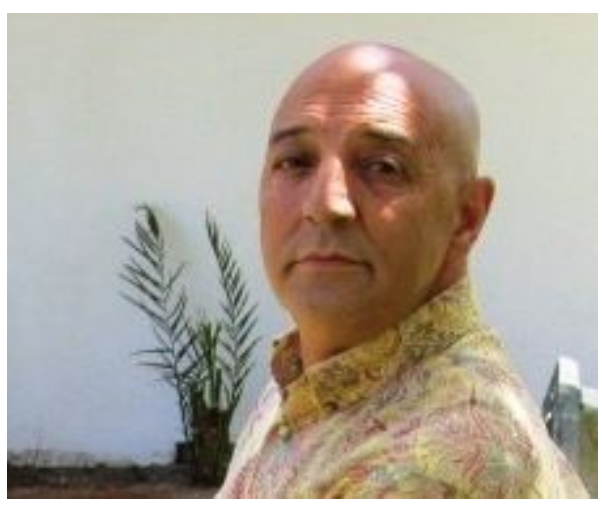

Angela Corrêa Ferreira Baalbaki ${ }^{1}$, Vanessa Gomes Teixeira Autor $2^{2}$

\begin{abstract}
1 Professora da Universidade do Estado do Rio de Janeiro (UERJ), Brasil. Doutorado em Letras pela Universidade Federal Fluminense (UFF), Brasil. E-mail: angelabaalbaki@hotmail.com

2 Doutoranda em Ciências da Linguagem na Faculdade de Letras da Universidade do Porto, Portugal. E-mail: vanessa_gomesteixeira@hotmail.com
\end{abstract}

Recebido em: 29/09/2016 | Aprovado em: 06/04/2017

DOI: 10.12957/interag.2017.25838

\section{Resumo}

Esta entrevista com Luis Ernesto Behares foi conduzida por membros do projeto "Estudos sobre bilinguismo: elaboração de materiais para o ensino de português para alunos surdos". Na entrevista, o professor uruguaio apresenta reflexões sobre a tendência da legislação sobre línguas de sinais, as formas de registro da língua de sinais uruguaia (LSU), a implementação de propostas de educação bilíngue para surdos, a aprendizagem de segunda língua em modalidade escrita e o ingresso de alunos surdos na educação superior. Além disso, também discute, a partir de sua vasta experiência acadêmica, a proposta de educação inclusiva para surdos.

Palavras-chave: Legislação Linguística; Educação

\begin{abstract}
This interview with Luis Ernesto Behares was conducted by members of the project Studies about bilingualism: elaboration of materials in order to teach Portuguese to deaf students ("Estudos sobre bilinguismo: elaboração de materiais para o ensino de português para alunos surdos"). In this interview, the Uruguayan professor presents reflections about the tendency of legislation on sign languages, the ways of recording the Uruguayan sign language, the implementation of proposals for bilingual education for deaf students, the acquisition of a second language in the written form and the entry of deaf students in higher education. Furthermore, he also discusses, throughout his vast academic experience, the proposal for inclusive education for deaf people.
\end{abstract}

Keywords: Linguistic Legislatio; Bilingual Education; 
Área temática: Comunicação.

Linha de extensão: Desenvolvimento Humano.

\section{Antes da conversa}

Questões relacionadas à educação de surdos, no Brasil, podem ser resgatadas desde o período imperial. No entanto, a proposta que ora se impõe pela própria comunidade surda brasileira remetem à educação bilíngue, em que a Libras é a primeira língua dos alunos surdos e a língua portuguesa na modalidade escrita é a segunda língua. Por ser considerada uma proposta muito recente - remontando à década de 1990 -, há grandes desafios a serem enfrentados e superados. Com esse intuito, o projeto de extensão "Recursos e Materiais para o ensino de Português para alunos surdos", realizado na Universidade do Estado do Rio de Janeiro (UERJ), buscou estabelecer contato contínuo com pesquisadores latino-americanos com larga experiência no campo de educação bilíngue para surdos. De fato, propusemos conduzir entrevistas com vários professores, tendo como objetivo propiciar um espaço de discussões e de contribuições teóricas e práticas para a área.

Imbuídos desse objetivo, realizamos os primeiros contatos Luis Ernesto Beharesi, professor Titular e Diretor do Departamento de Ensino e Aprendizagem, pertencente ao Instituto de Educação da Faculdade de Humanidades e Ciências da Educação (FHCE) da Universidade da República (UdelaR), em Montevideo, Uruguai. Por seu turno, o diálogo estabelecido entre o professor Behraresii e as instituições brasileirasiii de ensino superior advém de longa data. Tal intercâmbio traduziu-se em elaboração de pesquisas, oferecimento de cursos de pós-graduação, realização de supervisão de estágio de pósdoutorado, convites para participação em eventos científicos, participação em comitês e em editoriais de periódicos científicos. Atualmente, desenvolve pesquisas nas linhas "Indagações no campo teórico do ensino", "Dimensões linguageiras do ensino e da aprendizagem" e "Ensino universitário" Destacamos que o professor Luis Behares possui 
uma extensa e reconhecida trajetória no campo de investigação e reflexão sobre a comunidade surda e língua de sinais do Uruguai.

Os questionamentos trazidos por suas pesquisas têm levado aos integrantes do projeto uma profunda reflexão sobre as línguas de sinais, a legislação direcionada a essa língua e, sobretudo, a educação bilíngue de surdos. A seguir, apresentamos a entrevista que foi realizada por escrito e, posteriormente, traduzida, constituída de cinco perguntas, concedida por Luis Ernesto Behares.

\section{Iniciando a conversa}

Entrevistadores: No Brasil, foi promulgada a chamada lei de Libras (Lei $n .^{\circ} 10.436$, de 24 de abril de 2002). Trata-se de uma lei que oficializa a língua como "meio legal de comunicação e expressão”. Em sua opinião, como essa visão de língua expressa na lei pode servir de contraponto a uma visão de língua como laço de inserção social, que agrupa uma comunidade e que também tem um papel fundamental no processo de constituição do sujeito?

Prof. Luis E. Behares: A lei federal brasileira n 10.436 é semelhante a um conjunto de leis aprovadas em diversos países em relação às línguas de sinais das comunidades surdas. Raramente, para discordância dos linguistas e de outros cientistas sociais, esse tipo de lei determina a titularidade dos direitos estabelecidos na própria comunidade em si, e o fazem tomando os indivíduos um a um. Aqui temos uma primeira questão a ser considerada: ao tratar-se de uma língua, sabemos que a propriedade dos direitos ou poderes deve assentar no grupo, que é a sua comunidade linguística. No entanto, essas leis, e no Brasil em particular, preveem que a titularidade cabe à pessoa surda como um indivíduo separado.

O modelo destas leis é a tradição jurídica internacional iniciada com a Declaração dos Direitos Humanos (Cf. ONU, 1948) e Convênios que ocorreram entre 1948 e 1992; essa tradição se inspira na estrutura doutrinária do direito comum, 
especialmente nos EUA, "ciumento" por não estabelecer direitos e deveres para o coletivo, já que se inspira em uma concepção francamente individualista das relações sociais. Por exemplo, no Pacto Internacional sobre Direitos Civis e Políticos (Cf. ONU, 1966) já há um direito linguístico individual, de acordo com a tradição mencionada como um direito humano universal, que lhe confere positividade jurídica (art.14), mas inclui também uma inovação: o direito humano universal a seu próprio idioma não tem como titular exclusivo o indivíduo, e essa titularidade é ampliada como "comum com os demais membros de seu grupo" (art.27).

O artigo 27 foi, sem dúvidas, o grande articulador político-jurídico das construções que estamos mencionando. Nele encontramos vários subterfúgios: dá aos estados a capacidade de decidir se há ou não minorias étnicas, religiosas ou linguísticas (o que implica uma imprecisão insustentável e grandes facilidades para o seu descumprimento); não se afirma “será dado”, mas "não será negado" o direito a utilizar seu próprio idioma (o que pressupõe uma possibilidade e não um estabelecimento) a expressão "minoria" foi substituída por "pessoas pertencentes a minorias" (já que o direito é da pessoa e não do grupo) e minimiza o fator linguístico comunitário mediante a expressão "em comum com os demais membros do seu grupo" (para negar a propriedade do grupo, mas, ao mesmo tempo, reconhecer algo de identitário do mesmo). De acordo com vários pesquisadores, o artigo 27 reflete a tensão entre os direitos individuais e os direitos das comunidades, e abre uma lacuna muito confusa sobre a questão de quem pode exercer ou reivindicar esses direitos.

Se olharmos para a própria tradição da Linguística e das Ciências Sociais, a noção de "idioma próprio" não pode se referir a um direito individual, cujo titular seria exclusivamente a pessoa, e sim essa "propriedade" parece estar além da individualidade e ser apoiada definitivamente nos "grupos" que se identificam como proprietários de um idioma em comum. No entanto, esta dualidade em termos de titularidade dos direitos de idiomas também esteve presente em outros documentos contemporâneos e posteriores ao Pacto de 1966. 
Por exemplo, na Carta Europeia das Línguas Regionais e Minoritárias da Comunidade Europeia (Cf. CMCE, 1992, art. 7, inc. 1) documento considerado avançado na consagração de direitos linguísticos, parece claro que a propriedade para estes se alicerça nos coletivos mais que nos indivíduos. Nele, se consagra o direito das "línguas" em si mesmas (utiliza-se esta expressão de forma excludente), tais como entidades históricas; portanto, a titularidade dos direitos nele consagrados se reverte aos grupos relacionados ou determinados pelas línguas, e deixa de ser de propriedade dos falantes como indivíduos particulares.

Mais tarde, em 1996, foi elaborado em Barcelona um documento mais "radical" e de maiores pretensões, a Declaração Universal dos Direitos Linguísticos (Cf. UNESCO, 1996), na qual são reconhecidos claramente dois tipos de direitos linguísticos: os individuais e os coletivos. Enfatiza-se neste documento que os direitos linguísticos individuais são derivados e se justificam pelo direito linguístico central de ser reconhecido como um membro de uma comunidade linguística. Assim, os direitos coletivos passam a ser efetivamente reconhecidos, embora de forma oblíqua, e deles serão desprendidos, por meio do pertencimento a um coletivo, os direitos individuais. $\mathrm{O}$ referente coletivo do gozo dos direitos linguísticos se apresenta neste documento através do termo comunidade linguística histórica: "[...] toda sociedade humana que, alicerçada historicamente em um espaço territorial determinado, reconhecida ou não, se auto-identifica como povo e desenvolveu uma língua comum como meio natural de comunicação natural e de coesão cultural entre seus membros. A denominação de língua própria de um território refere-se ao idioma da comunidade historicamente estabelecida neste espaço" (Cf. UNESCO, 1996, Seção 1, inc. 1)iv. Referi-me a essa questão em alguns trabalhos recentes (Cf. BEHARES, 2013a; 2013b; prelo), concluindo que há um grave problema na legislação linguística quando se deixa de abordar o fato evidente de que as línguas não são de propriedades privadas, e sim bens coletivos de um determinado grupo, uma vez que se não existisse tal grupo também não se poderia falar sobre a língua. No caso das línguas de sinais, e dada sua tradicional relação com o campo da "deficiência", esta afirmação é, pelo menos, opaca. 
Deve-se levar em conta que as leis de línguas de sinais, e a brasileira entre elas, talvez não pertençam, stricto sensu, à legislação linguística, mas também à legislação da deficiência. A discussão sobre o que estamos argumentando se refere a comunidades linguísticas (e a sujeitos membros dessas comunidades) que têm uma língua como determinante de sua historicidade e de sua existência interpessoal. Nesses casos, são incluídos os grupos indígenas, humanos refugiados de seu território original, aqueles que vivem em uma região que conserva uma língua minoritária e todos os casos deste tipo. É nesse mesmo conjunto que se inclui a população surda brasileira, ou seja, o agrupamento humano marcado por sua diferença lingüística-cultural?

De fato, a legislação linguística brasileira consagra (Constituição Federal, Art. 13) uma única "língua oficial" da Federação - chamada "Língua Portuguesa" - (Cf. BRASIL, 1988); diferentes leis, emendas e atos administrativos federais, estaduais e municipais legislam sobre o reconhecimento de outras línguas existentes no país, especialmente as indígenas. A lei da língua de sinais se insere nesse movimento de oficialização e reconhecimento de línguas? A meu ver, e semelhante a outras leis de línguas de sinais existentes em vários países, a língua de sinais é sempre promulgada como um instrumento compensatório da deficiência natural de seus potenciais usuários e não como o determinante de uma comunidade linguístico-cultural diferente.

De um ponto de vista, estas leis sobre línguas de sinais promulgadas de forma independente, e na ausência de uma legislação linguística geral e orgânica do Estadosociedade, costumam apoiar sobre as bases ideológicas que definem os surdos como um grupo de deficientes. Trata-se, segundo a certa terminologia clássica (Cf. KLOSS, 1977; MAY, 2010), de leis tolerantes, caracterizadas pela benevolência para uma minoria da população e para seus atributos sociais e culturais; não são, mas que por efeitos indiretos, leis de promoção dessas comunidades, no sentido de potenciar sua diferença social e cultural (incluída, em primeiro lugar, a propriedade de uma língua) e de serem outorgados a essas, direitos e poder.

Menos ainda são leis de reconhecimento da condição histórica das línguas de sinais e dos fatores culturais que estão associados a elas. Alguns países avançaram muito 
nesse sentido, o que se deu em parte numa experiência recente no Uruguai, mas não o suficiente para desacreditar radicalmente a atribuição da surdez a uma deficiência e para estabelecer ferreamente sua realidade de comunidade linguístico-cultural.

As relações que este tipo de lei estabelece entre as línguas de sinais, seu uso pelas pessoas surdas e as obrigações atribuídas aos diversos agentes que atendem pessoas surdas são sempre de caráter instrumental; mais ou menos delimitado; em certo sentido são do tipo “ortopédico" (Cf. PELUSO, 2009). No caso da lei brasileira, a Libras é apenas reconhecida como "meio legal de comunicação e expressão" (art. 1), caracterizada como "sistema linguístico de natureza visual-motora, com estrutura gramatical própria” e "oriunda (sic) de comunidades de pessoas surdas do Brasil". Dessa forma, em um instrumento disposto para certos usos, se perde grande parte do que é de sua própria natureza: a de ser uma ordem na qual é constituída a comunidade e os sujeitos que a integram. O problema é semelhante ao da lei uruguaia específica de reconhecimento da LSU (Cf. URUGUAI, 2001).

Apesar das limitações que mencionamos, temos de reconhecer que essas intenções de promulgar leis pode ser positiva. A legislação linguística contribuiu para situar as línguas de sinais no espaço político e social. Para que este efeito não se perca e tudo esteja no plano da benevolência naturalizada, muito trabalho será necessário, sobretudo nos modelos educativos para a primeira infância.

Entrevistadores: Assim como a Libras, a Língua de Sinais Uruguaia (LSU) ainda não apresenta representação escrita oficializada. Levando em conta essa questão, quais são as formas de registros existentes para a documentação dessa língua? Há lutas políticas dos surdos uruguaios para a consolidação da modalidade escrita da LSU? Ou para que o registro dessa língua espaço-visual deva ser feito por meio de filmagem e/ou outros processos?

Prof. Luis Behares: Como foi dito, a LSU, semelhante às outras línguas de sinais do mundo, não tem uma modalidade escrita própria, nos formatos tradicionais das línguas 
faladas. Nada indica que esta escrita não seja possível, mas, de fato, ainda não foi estabelecida. Creio ser necessário fazermos uma distinção: por um lado a inexistência de uma escrita geral e convencional (do tipo tradicional) que seja de uso de grande parte da comunidade linguística, e por outro lado a definição da situação da LSU como estritamente imersa na "oralidade" (ou seja: na dimensão exclusiva da comunicação face a face). Se a primeira afirmação é claramente adequada, a segunda não é.

A LSU foi ocupando espaços importantes no cenário público desde 1983 (Cf. BEHARES; BROVETTO; PELUSO. 2012), como o idioma utilizado para o ensino, para a tradução televisiva e de atividade política, jurídica, etc., a partir de vários desenvolvimentos sociais, amparados ou não por legislação específica. Hoje em dia a LSU aparece amplamente em formas de registros próprias da escrita, do mais variado tipo. Ao mesmo tempo, as comunidades surdas incluem o que poderia ser chamado de setores letrados intraétnicos, ou seja, pessoas surdas que registram e difundem seu pensamento e produtos acadêmicos ou artísticos por meio da LSU e há áreas formais para fazê-lo. A forma mais usada é o vídeo ou DVD, com as vantagens que a informática vem proporcionando para o uso, a edição e a distribuição destes produtos e em particular, o auxílio da internet.

Os surdos são conscientes da importância que estes avanços têm para a prevalência, a identidade e o futuro de suas comunidades. Os intelectuais surdos da comunidade têm assumido fortemente essa responsabilidade nos últimos anos. Os âmbitos públicos de formação vinculados à surdez no país, como a Universidade da República e a Administração Nacional de Educação Pública, assim como algumas instituições privadas e das próprias comunidades surdas, têm sido bastante receptivos à importância ao acesso da comunidade surdo ao letramento em sua própria língua. Como é evidente, este processo vem produzindo mudanças relevantes na língua, na ordem de sua gramatização, estandarização e crescimento formal e funcional, tal como descrito na literatura (Cf. PELUSO, 2011; FOJO, 2012).

Atualmente, há um intenso trabalho de professores surdos e ouvintes vinculados à Faculdade de Humanidades e Ciências da Educação na sua área de estudos surdos, 
destinada ao desenvolvimento de modos de registros da língua e dos produtos da mesma. A formação que desde 2009 era direcionada exclusivamente a intérpretes foi redesenhada para incluir também a formação de tradutores surdos da LSU para o espanhol e viceversa, a de lingüistas de LSU e a de técnicos no registro da LSU (Cf. TUILSU-FHCE, 2014). Em termos de pesquisa, o programa TRELSU (Cf. PELUSO e BONILLA, 2010), dirigido por Leonardo Peluso, fornece contribuições teóricas, metodológicas e técnicas.

Entrevistadores: A educação bilíngue brasileira para surdos prevê o ensino de Libras como primeira língua, e a aprendizagem de Português na modalidade escrita como segunda língua. No caso do Uruguai, esse ensino estabelece a LSU como L1 do aluno surdo e o ensino da modalidade escrita do Espanhol como L2? Qual a posição da comunidade surda uruguaia em relação à obrigatoriedade em aprender outra língua além da sua primeira língua?

Prof. Luis Behares: $O$ processo de educação bilíngue para surdos no Uruguai começou em 1987, com a aprovação de uma Proposta para a Educação Primaria (Cf. CONSEJO DE EDUCACIÓN PRIMARIA, 1987), que está em vigor desde então, continuou em 1996 com uma proposta específica para o ensino secundário e foi introduzido à Universidade em 2006. Ao longo desses vinte anos, o processo foi desencadeado por meio de parcerias de formação em diversos organismos públicos e privados. Deve-se levar em conta que os níveis Primário, Secundário e Superior no Uruguai são autônomos e não respondem diretamente às iniciativas provenientes do Ministério da Educação; portanto, planos em cada nível foram instrumentalizados de forma independente.

Em 2008, a Comissão de Política Lingüística na Educação Pública reforçou com caráter geral, a recomendação da Educação Bilíngue para Surdos, estabelecendo parâmetros ideais gerais, no marco do estabelecimento de políticas linguísticas para todos os aspectos que podiam ser relevantes no país - as outras línguas e as minorias, o ensino de línguas estrangeiras, o ensino do espanhol, etc. - (Cf. ANEP, 2008). 
Quanto à pergunta, as propostas desde 1987 e referendadas em 2008, a nível nacional e global, promovem a educação bilíngue para surdos, incluindo a LSU como língua de instrução básica e o Espanhol escrito como segunda língua. A LSU não é ensinada para crianças ou adolescentes surdos, já que se utiliza na educação como a língua natural deles por professores ouvintes e educadores surdos. Existem, certamente, espaços para o estudo da LSU, sua gramática, a consciência metalinguística que lhe é própria, sua textualidade através de registros ao alcance da idade dos alunos, como em qualquer língua de instrução em que se é dado por consolidado um conhecimento natural. $\mathrm{O}$ espanhol escrito é introduzido como segunda língua desde o início do processo. Não há rejeição por parte dos alunos surdos ou das comunidades surdas a esse ensino sistemático do Espanhol escrito.

É necessário levar em conta alguns fatores que diferenciam o processo uruguaio do brasileiro, de acordo com meu conhecimento e opinião.

Em primeiro lugar, o Uruguai é um país tradicionalmente de alto nível de letramento - com taxas de analfabetismo menores que 4\% e com índices de leitura de 87 páginas por pessoa por mês - (Cf. BAR-HYLAN,2004), dado talvez mais imaginário do que real, mas com forte valorização da cultura letrada. As comunidades surdas, salvo exceção, têm esse modelo geral letrado como um valor para alcançar suas inclusão social e empoderamento. Ainda assim, as "escritas surdas" poderiam ser consideradas como variedades do espanhol fortemente interferidas pela LSU e o sistema educativo tem, nesse ponto, um problema importante não resolvido.

Em segundo lugar, deve-se notar que os alunos surdos não participam, como raríssimas exceções, de programas de inclusão.

O próprio projeto da educação bilíngue supõe, segundo os documentos existentes já citados, a escola especializada para surdos. No nível do ensino primário, há várias escolas bilíngues em todo o país e, em algumas cidades menores, aula para surdos em escolas regulares; no ensino secundário são incorporadas aulas para surdos nos liceus públicos, essas predominantes em alguns liceus de Montevidéu; a nível universitário, com exceção dos estudos da área de surdez da Facultad de Humanidades y Ciencias, os 
estudantes surdos dispõem de um intérprete de LSU ao longo da realização da disciplina. Esta realidade instaura a comunidade surda na escola, em que as relações com a variedade escrita do espanhol são processadas pelos alunos de forma coletiva, o que é bastante diferente do caso de uma criança surda ser inserida solitariamente em uma sala de aula com estudantes ouvintes.

Em terceiro lugar, os documentos reguladores de políticas linguísticas para a educação no Uruguai já citados impuseram o ideal multilíngue, pelo qual os estudantes deverão estudar, além dos estudos acerca de sua língua materna - Espanhol, Português ou LSU segundo a Lei da Educação (Cf. URUGUAY,2008) -, Inglês e Português como línguas estrangeiras e segundas obrigatórias (em torno de 6 anos a primeira e 3 a segunda) e uma terceira língua estrangeira optativa (Italiano, Francês, Alemão, etc., de 3 anos de estudos). Nesse marco de referência que vem sendo instrumentalizado gradualmente desde 2009, a aquisição de uma segunda língua para um estudante surdo é um fato natural.

Entrevistadores: Observou-se, a partir da primeira década do século XXI, uma intensa inserção de alunos surdos no ensino superior. Algumas iniciativas podem ser verificadas no Uruguai e no Brasil, por exemplo, como a criação da Tecnicatura Universitária em Interpretação LSU (Língua de Sinais Uruguaia) - Espanhol (UdelaR), a implementação do curso Letras-Libras, a princípio na Universidade Federal de Santa Catarina (UFSC), e do curso Bilíngue de Pedagogia, do Instituto Nacional de Educação de Surdos (INES). Com isso, começa a se pensar em uma proposta educacional voltada para a formação especializada desse alunado. Em sua opinião, qual é o papel dessas iniciativas para a inclusão de surdos em novos espaços na sociedade e de que forma elas ajudam no empoderamento dessa comunidade?

Prof. Luis Behares: Concordo que a inclusão de alunos surdos no ensino superior, cada vez com melhores resultados, é uma grande novidade em nosso país, que contrasta claramente com as experiências de outros países da região. Neste caso, devemos distinguir 
o acesso geral da população surda a todo o universo da formação superior, por um lado, e a inclusão de pessoas surdas em programas específicos ligados a disciplinas relacionadas com a surdez e a língua de sinais, por outro.

No primeiro dos casos, em 1983, quando eu comecei a trabalhar com a temática da surdez, de um volume de 84.000 estudantes, a Universidade da República tinha um único aluno surdo no curso de Arquitetura e dois alunos com perda auditiva leve no curso de Economia (o que representa 0,001\%). Segundo dados de 2012 (Cf. ÁLVAREZ, 2012), havia 14 alunos surdos na Universidade da República e 1 em uma universidade privada (neste caso, não existem dados sobre outros tipos de problemas de audição) em um conjunto de 130.000 estudantes universitários, o que altera o percentual para 0,01\%, distribuído entre as Faculdades de Ciências, Direito, Arquitetura, Belas Artes, Economia, Química e Medicina.

É uma alteração significativa, que pode ser explicada por diversos fatores. O principal, creio eu, é o êxito dos programas de educação bilíngüe implementados, embora com muitos defeitos, nos últimos 25 anos. De fato, se medirmos o sucesso a partir da correlação de alunos surdos nos três níveis educativos, teremos: 120 alunos do ensino fundamental, 45 alunos no ensino secundário e 15v no ensino universitário, o que tem como resultado $37,50 \%$ de continuidade primário-secundário, 33,33\% de continuidade do ensino secundário-universitário e $12,5 \%$ de continuidade do ensino primáriouniversitário. São excelentes resultados, em minha opinião.

Um segundo fator que explica isso, obviamente, são os serviços de interpretação e adaptações curriculares que tornam mais viável o acesso e a permanência desses estudantes na Universidade da República. Finalmente, e talvez o mais importante, as mudanças sociológicas que têm sido operadas de maneira conjunta nas comunidades surdas.

Se nos concentrarmos na inclusão de pessoas surdas em programas específicos vinculados a disciplinas relacionadas à surdez ou à língua de sinais, como vocês apontam, desde 2009, o Uruguai avançou muito através da área de Estudos Surdos da Facultad de Humanidades y Ciencias de la Educación. Com várias ofertas e carreiras em todo o país, 
neste espaço trabalham já como docentes nove surdos, com titulação de educação terciáriavi ou superior universitário, e assistem como estudantes um conjunto muito amplo de jovens surdos, que será ampliado com a nova oferta da carreira de Tecnólogo em Interpretação e Tradução, que deverá abrir em 2016.

Em relação ao Brasil, se bem conheço os programas citados por vocês, não posso dar uma opinião definitiva. Parece-me claro que o Brasil atingiu grande êxito no ensino superior para surdos em poucos anos, especialmente com programas específicos ligados a disciplinas relacionadas à área da surdez ou à língua de sinais. A meu ver, seguindo uma característica tradicional do sistema brasileiro, optou-se pela renovação de cima para baixo, enquanto que no Uruguai, seguindo outra tradição que lhe é própria, a instrumentalização deu-se de baixo para cima. Cada modelo tem suas vantagens e desvantagens, é claro, mas ambos têm contribuído a seu modo para abordar as comunidades surdas no âmbito educacional.

Entrevistadores: Apesar da proposta de inclusão, ao menos no Brasil, visar à educação para todos, na prática, ela tem sido criticada por muitos professores que trabalham em escolas regulares. Isso porque eles explicam que integrar um aluno surdo ao espaço físico da sala de aula sem pensar em suas especificidades não significa incluir, e sim, muitas vezes, excluir. Em sua opinião, quais os obstáculos que ainda devem ser superados para que de fato haja um ensino que respeite as necessidades desses alunos?

Prof. Luis Behares: A opinião dos professores brasileiros a respeito dos problemas introduzidos pela ideologia pedagógica que chamamos de "inclusão", em geral, e para os grupos surdos em particular, tem uma forte carga de evidências. Alguma coisa está errada na inclusão de crianças surdas na sala de aula regular, que não é apenas um problema de instrumentação pedagógica.

Em 1987, quando se começou a implementar no Uruguai os primeiros programas do que se denominava "integração dos deficientes à sala de aula regular", a Comissão que estudava a Proposta de Educação Bilíngüe para Surdo, já citada, advertiu 
que esse tipo de programa e a educação bilíngue em si são contraditórios (Cf. BEHARES, 1987; GABBIANI e BEHARES, 1987; BEHARES, 1993). Por esta razão, a Proposta não inclui estratégias do que hoje chamamos de "inclusão", sustentando a necessidade de manter as escolas específicas para crianças surdas, uma estratégia que tem sido mantida ao longo do tempo.

A questão da inclusão é complexa. Ela tem duas justificativas: inicialmente, esteve ligada à superação dos parâmetros característicos das concepções de deficiência e seu questionamento no marco da educação especial dos anos de 1980. As ideias pedagógicas para desarticular a deficiência medicalizada e substituí-la por uma visão mais positiva ("necessidades educativas especiais", "capacidades diferentes", etc.) deram muitos resultados no que diz respeito à grande maioria das chamadas deficiências. Mais tarde, nos anos de 1990, a noção de inclusão abriu-se em direção a visões de teor mais sociológico, para abarcar, mediante a educação os setores sociais ou culturais marginalizados, entre os quais as populações "deficientes". Em ambos os casos são modelos que vão em uma direção bastante diversa em relação às pedagogias da diferença, sobretudo, quando se trata de grupos diferentes em sua língua e cultura.

Nestes casos, a inclusão de uma criança proveniente de uma cultura linguística diferente da língua majoritária em uma sala de aula produz o isolamento desse indivíduo com respeito à sua comunidade de origem e o coloca na terrível atitude de conviver somente com a cultura majoritária.

Os programas de inclusão de crianças surdas à sala de aula comum ou regular diferenciam-se de uma verdadeira estratégia de educação bilíngue por dois fatores fundamentais: a) a inclusão é destinada estrita e diretamente ao indivíduo, a ação de aproximá-los em um mesmo espaço educacional produzirá a igualdade de oportunidades e a convivência social, ao passo que a educação bilíngue incorpora a comunidade de pertencimento à escola, e não apenas o indivíduo, e tende a situar a igualdade social no plano das relações inter-identitárias;

b) na inclusão, os fatores da identidade e atividade linguística dos alunos e seus professores se organizam em torno da instrumentalidade das línguas, enquanto que a 
educação bilíngue parte de uma concepção de língua como ordem constitutiva da identidade social, o conhecimento e o sujeito.

Um programa de educação bilíngue consiste precisamente em reunir em um mesmo espaço duas heranças culturais e linguísticas para que convivam e produzam de forma complementar, mas estas estratégias de integração social não estão focadas no indivíduo, mas em sua condição de sujeito, efeito de um conflito histórico de pertencimento.

Entrevistadores: Outra questão que surge a partir da proposta de educação inclusiva, é qual escola que melhor atende às necessidades da comunidade surda: a escola especializada, voltada apenas para esses alunos, ou a escola regular, na qual há alunos surdos e ouvintes. Caso seja possível elencar um modelo escolar, qual dos dois seria o mais adequado para alunos surdos sinalizantes que, por força da lei e demais coerções, devem aprender a modalidade escrita da língua oficial do seu país?

Prof. Luis Behares: No mesmo quadro de referência com o qual respondi a pergunta anterior, devo dizer que creio que a melhor forma hoje em dia possível para a educação de surdos implica a permanência do que vocês chamam de "escola especializada".

Por muitos fatores, com os quais podemos ser inteiramente de acordo, a tradição da escola especializada ou especial foi muito ligada à medicalização, à confusão entre a escola e a clínica e a concepção oralista de tipo terapêutico. Essa não é a escola que melhor atende às necessidades das pessoas surdas e muito menos das comunidades surdas. Acredito que demos um grande salto se pensarmos por um novo rótulo: "escolas surdas".

Uma "escola surda" é aquela em que a comunidade surda é incorporada ao sistema educacional sem deixar de ser surdo, e sem perder o domínio de sua própria língua, sua cultura, suas tradições e suas projeções para o futuro. A educação bilíngue implica uma comunidade surda que vai ao encontro da cultura da comunidade majoritária dos ouvintes, uma comunidade de falantes de língua de sinais (Libras, LSU, 
etc.) que se encontra, se vincula e se engrandece com o seu contato com os bens da comunidade de falantes de outra língua, a chamada "oral" (Português, Espanhol, etc.). Dessa forma, não é a escola especial tradicional, em que os ouvintes "atendem" aos surdos, como ocorreu em demasia com os programas de inclusão individual, de forma velada, mas sim uma escola surda.

Neste sentido, a escola de surdos não é nada diferente de uma escola ideal para membros das comunidades linguísticas diferentes à majoritária, por exemplo, as escolas Arauá, Kurripato, Pomerana ou Husrriqueana, se levarmos em conta todas as outras línguas existentes no Brasil. Esta escola deve tornar-se um ponto de encontro da comunidade de falantes de língua de sinais com a cultura geral majoritária de falantes do Português e do Espanhol, e afastar todo componente que a vincule com o médico ou clínico. De fato, as práticas médicas e clínicas não fazem parte do ensino regular, ainda que também sejam importantes e necessárias, mas sempre realizadas fora do ambiente escolar típico.

O Brasil já tem amplo desenvolvimento em matéria de educação de comunidades linguísticas diferentes a da Língua Portuguesa. Contudo, não é claro para mim que a comunidade de falantes de Libras se inclua, sem mais, nesse conjunto.

\section{Considerações finais}

A partir da fala de Luis Ernesto Behares, concluímos que o reconhecimento do status linguístico das línguas de sinais é apenas o primeiro passo para a inclusão da comunidade surda na sociedade. No caso do Brasil, por exemplo, a forma como a inclusão está acontecendo, muitas vezes, exclui a comunidade surda, pois apenas a integra no espaço físico da sala de aula, sem respeitar suas especificidades e disponibilizar estrutura que atenda às suas necessidades. Propor a suposta inclusão sem pensar nas especificidades dos alunos surdos também mantém essa lógica excludente.

Em relação à lacuna no que diz respeito à formação do professor, podemos destacar que são raras as discussões sobre os temas Surdez e Ensino de Português como 
L2 nos cursos de formação. Isso sinaliza que, mesmo tendo interesse em aprender mais sobre a comunidade surda e suas especificidades, o professor pode ter dificuldades em adaptar ou elaborar práticas pedagógicas para esse público. Cabe ressaltar que, para muitos, é grande a surpresa de ver que os surdos tomam o Português como uma segunda língua e não como L1. Isso gera idiossincrasias e distorções no momento da elaboração e adaptação de materiais, assim como na própria prática pedagógica.

Pensar na inclusão do aluno surdos na sala de aula regular ultrapassa a adaptação de materiais: é necessária uma mudança social e cultural na nossa Educação atual.

\section{Referências Bibliográficas}

ÁLVAREZ, C. (2012) Acerca de los servicios de interpretación en la Universidad de la República y en la Universidad del Trabajo del Uruguay. En: 5to Foro de Lenguas de ANEP. Montevideo: Consejo Directivo Central de ANEP, pp. 73-75.

ANEP (2008). Documentos da Comissão de Políticas Linguísticas na Educação Pública. Montevideo: Administración Nacional de Educación Pública/Consejo Directivo Central.

BAR-HYLAN, J. (2004) Uruguayan literacy tradition and ideology. Culture \& education, vol. 14 , no 4 , pp. 36-52.

BEHARES, L. E. (1987) Sordera e Identidad Social. Montevideo: Universidad de la República.

(1993) El desarrollo de las Habilidades verbales en el niño sordo y su aprovechamiento pedagógico. En: XI Congreso Nacional de AEES-FEPAL, Mérida (España): pp. 209-230. 
(2013a). Hablantes y Comunidades: Crítica de la noción estándar de Derechos Lingüísticos. In: FARENZENA, N. (Org.) VI Encontro Internacional de Investigadores de Políticas Lingüísticas. Porto Alegre: Universidade Federal de Rio Grande do Sul Associação de Universidades Grupo Montevideo, pp. 33-41. 2013.

(2013b). Notas sobre la noción de Derechos Lingüísticos ¿Quién es su titular? RDPL-Revista Digital de Políticas Lingüísticas (Córdoba), Año 4, vol. 4. pp. 37-58.

(aceito para publicação) Opciones educativas culturalmente sensibles a la diversidad y la implementación de los derechos lingüísticos. Educação. Revista do Centro de Educação (UFSM).

; BROVETTO, C. Y L. PELUSO. (2012) Language policies in Uruguay and Uruguayan Sign Language (LSU). Sign Language Studies, vol. 12, n. 4: p. 519-542.

BRASIL. (1988) Constituição da República Federativa do Brasil. Brasilia: Ministério da Educação.

(2002). Língua Brasileira de Sinais. LEI No 10.436, de 24 de abril de 2002. Dispõe sobre a Língua Brasileira de Sinais - Libras e dá outras providências. Disponível em: <portal.mec.gov.br/arquivos/pdf/lei10436.pdf>. Acesso em: 17 jun.2014.

CONSEJO DE EDUCACIÓN PRIMARIA (1987). Propuesta para la implementación de la educación bilingüe en el sordo. Montevideo: Consejo de Educación Primaria.

CMCE- Comitê de Ministros do Conselho da Europa. (1992) Carta Europeia das línguas regionais e minoritárias, elaborada em Estrasburgo em 5 de novembro de 1992. Disponível em: 〈www.consello.org/pdf/cartaeuropea92.pdf>. Acesso em: 20 jan. 2013. 
FOJO, A.; MASSONE, M. I. (2012). Estructuras Lingüísticas de la Lengua de Señas Uruguaya. Montevideo: FHCE.

GABBIANI, B. y L. E. BEHARES (1987) The deaf child and the diglossic context of deaf education in Uruguay. En: Proceedings of the XIVTh. International Congress of Linguist. Berlín: Akademie Verlag.

KLOSS, H. (1977) The American Bilingual Tradition. Rowley: Newbury House.

MAY, S. (2010). Derechos lingüísticos como derechos humanos. Revista de Antropología Social, 19, 131-159.

ONU- Organização das Nações Unidas. (1948) Declaração Universal dos Direitos Humanos. Disponível em: <www.un.org/es/documents/udhr>Acesso em: 20 jan. 2013. (1966) Pacto Internacional dos Direitos Civis e Políticos. Página da Oficina do Alto Comisionado das Nações Unidas para os Direitos Humanos. Disponível em: <www2.ohchr.org/spanish/law/ccpr.htm>. Acesso em: 20 jan. 2013.

PELUSO, L. (2009). Ley de reconocimiento de la LSU: ¿política lingüística u ortopedia? In: IV Encuentro Internacional de Investigadores de Políticas Lingüísticas. Santa Maria: Universidade Federal de Santa Maria-Asociação de Universidades Grupo Montevideo, 170-187.

. (2011) Acerca de los procesos de gramatización de la LSU: descripción y alcances. In BEHARES, L. E. (Org.) V Encuentro Internacional de Investigadores de Políticas Lingüísticas. Montevideo: Universidad de la República-Asociación de Universidades Grupo Montevideo, pp. 105-110. 
; BONILLA, F. (2010). Hacia un descriptor del nivel fonológico de la LSU. Lengua de Señas e Interpretación. Montevideo, № 1, pp. 29-56.

; VAL S. (2012). Léxico TRELSU: caracterización, aspectos teóricos metodológicos y manual de uso. Lengua de Señas e Interpretación, Montevideo, № 3, pp-31-50.

TUILSU-FHCE. (2014) Plan de Estudios de la Carrera de Tecnólogo en Interpretación y Traducción LSU. Español.

UNESCO. Organização das Nações Unidas para a Educação, a Ciência e a Cultura. (1996) Declaração Universal dos Direitos Lingüísticos. Página Oficial da UNESCO. Disponível em: $\langle$ http://www.unesco.org/cpp/sp/declaraciones/linguisticos.htm>. Acesso em: 20 jan. 2013.

URUGUAY. (2001). Ley No 17. 378. Reconócese a todos los efectos a la Lengua de Señas Uruguaya como la lengua natural de las personas sordas y de sus comunidades en todo el territorio de la Republica. Montevideo: Parlamento del Uruguay. Acesso em: <http://200.40.229.134/leyes/AccesoTextoLey.asp?Ley=17378\&Anchor>

(2008). Lei. no 18.437. Lei Geral da Educação. Montevideo: Dirección Nacional de Impresiones y Publicaciones Oficiales. Esta lei estabelece o Espanhol do Uruguai, o Português do Uruguai e a Língua de Sinais Uruguaia como "línguas maternas dos cidadãos uruguaios" e obriga o seu reconhecimento no modelo 
${ }^{\text {i }}$ PROFESSOR TITULAR E DIRETOR DO DEPARTAMENTO DE ENSINO E APRENDIZAGEM DO INSTITUTO DE EDUCAÇÃO DA UNIVERSIDADE DA REPÚBLICA (UDELAR). Montevidéu, Uruguai, $\underline{\text { lbeharesc@yahoo.com. }}$

ii Também é Coordenador do Núcleo Disciplinar de Educação para a Integração, Associação de Universidades do Grupo Montevidéu Também foi professor adjunto do Instituto de Linguística (FHCE), de 1979 a 2005, e Presidente da Comissão Nacional de Políticas Linguísticas na Educação Pública de Uruguay, entre 2006 e 2009. Tem em torno de 20 livros publicados, além de 100 artigos completos em revistas e anais de congresso sobre diferentes enfoques e temáticas relacionados à Surdez, à Psicologia e à Psicanálise, à Linguística, à Fronteira Brasil-Uruguai e às Teorias de Ensino. Já atuou como professor convidado em programas de pós-graduação em diversas universidades, em países como Itália, Argentina, Venezuela, México e, especialmente, no Brasil. Tem realizado diversas atividades de gestão acadêmica e de editoria, participado de diferentes equipes multidisciplinares de pesquisa, orientado teses e monografias, prestado consultorias de diversas naturezas e desenvolvido dezenas de atividades de natureza extensionista ao longo das últimas três décadas.

iii Podemos citar algumas delas: Universidade Estadual de Campinas (UNICAMP); Universidade Federal de Santa Maria (UFSM); Universidade Federal do Rio Grande do Sul (UFRGS); Universidade Federal da Bahia (UFBA), entre outras.

iv $\mathrm{O}$ documento também se ocupa, por via de exceção, com as línguas que não estão ligadas a um território, como seria o caso, mutatis mutandis, das línguas de sinais.

v Dados aproximados. Levamos em conta que o Uruguai tem uma população total de cerca de 3.200.000 habitantes, com a qual a população de surdos incorporados ao Sistema Nacional de Educação é de 0,006 $\%$, e paga tributo à proporção diminuída de indivíduos nas etapas educativas da vida na demografia nacional, ao qual se devem somar os avanços no atendimento em saúde perinatal dos setores populares na última década. Não foram incluídos aqui os estudantes surdos que fazem parte de programas terciários, de Formação Docente ou de cursos profissionalizantes.

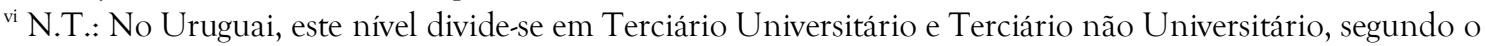
decreto 308/995, aprovado em 11 de agosto de 1995. O Terciário Universitário inclui a Universidade da República (autônoma e gratuita), assim como quatro universidades privadas (Universidade Católica, Universidade ORT, Universidade de Montevidéu e Universidade da Empresa). O Terciário não Universitário inclui Institutos de Formação Docente, Centro de Design Industrial no âmbito do Ministério de Educação e Cultura, Escola Militar, Escola Naval e Escola Militar de Aeronáutica no âmbito do Ministério de Defesa, Escola Nacional de Polícia no âmbito do Ministério de Interior, e Institutos Privados. 